\title{
Multimodal Therapy is a Better Choice for Patients with Brain Metastasis from Cervical Cancer
}

This article was published in the following Dove Press journal: Cancer Management and Research

\author{
Shuai Sun \\ Xin Lian \\ Xiaoliang Liu \\ Jiabin $M a(\mathbb{D}$ \\ Xiaorong Hou (D) \\ Fuquan Zhang $\mathbb{D}$ \\ $\mathrm{Ke} \mathrm{Hu}$ (iD
}

Department of Radiation Oncology, Peking Union Medical College Hospital, Chinese Academy of Medical Sciences and Peking Union Medical College, Beijing 100730, People's Republic of China
Correspondence: Fuquan Zhang Department of Radiation Oncology, Peking Union Medical College Hospital, Chinese Academy of Medical Sciences and Peking Union Medical College, No. I Shuaifuyuan Wangfujing, Dongcheng District, Beijing 100730, People's Republic of China

$\mathrm{Tel}+86-10-6915-5485$

Fax +86-10-65I 24875

Email zhangfq@pumch.cn

$\mathrm{Ke} \mathrm{Hu}$

Department of Radiation Oncology, Peking Union Medical College Hospital, Chinese Academy of Medical Sciences and Peking Union Medical College, No. I Shuaifuyuan Wangfujing, Dongcheng District, Beijing 100730, People's Republic of China

Tel +86- I0-69| 55482

Fax +86-10-65I 24875

Email huke8000@I63.com
Objective: To evaluate the prognostic factors and optimal management of cervical cancer patients with brain metastasis (BM).

Materials and Methods: We retrospectively reviewed the medical records of 7098 consecutive patients with cervical cancer from January 2000 to December 2019. Data for a total of $24 \mathrm{BM}$ patients with cervical cancer were analyzed retrospectively in the present study.

Results: The incidence of BM from cervical cancer in our institution was $0.38 \%$. The mean survival time was 7.2 months (median 6.2 months, 0.1-21.2 months). In the univariate analysis, the histopathology of neuroendocrine cancer, 2018 FIGO stage, Karnofsky performance status (KPS) at BM diagnosis, and treatment strategy were identified to be significant prognostic indicators for the survival of patients with BM from cervical cancer. In the multivariate analysis, KPS, chemotherapy, and radiotherapy were independent prognostic factors for survival. Recursive partition analysis (RPA) appeared to be a better prognostic tool than the other prognosis scoring classification systems.

Conclusion: When patients with BM from cervical cancer have good performance status and undergo comprehensive treatment, such as radiotherapy and chemotherapy, their survival time could be significantly prolonged. Patients with surgical indications may get better survival by postoperative radiotherapy and chemotherapy. Patients with BMs $\geq 3$ may get better survival by whole-brain radiotherapy. But further studies are needed regarding the selection of surgical indications and radiotherapy modes. The prognosis scoring classification system for BM from cervical cancer needs to be improved.

Keywords: cervical cancer, brain metastasis, prognostic factors

\section{Introduction}

Cervical cancer is the most common cancer in women. The common metastatic sites are the lymph nodes, liver, lung, bone, etc. Brain metastasis (BM) is very rare. The incidence of BM from cervical cancer in the clinic is $0.4-2.3 \%{ }^{1-8}$ Most BM occurs approximately $1.5-2$ years after the diagnosis of cervical cancer. ${ }^{4,5,9,10}$ The median survival time is $2-8$ months, ${ }^{5,8,11-15}$ and there are no standard therapies. Additionally, RPA (recursive partition analysis) and GPA (Graded Prognostic Assessment) are currently the most commonly used prognosis scoring classification systems for BM. Uterine-GPA was also proposed based on prognostic factors for BM of uterine tumors. ${ }^{14}$ Many other prognosis scoring classification systems such as BS-BM (Basic Score for Brain Metastasis) and GGS (Golden Grading System) are mainly used in SRT. 
This paper analyzed the prognostic factors and treatment mode of cervical cancer patients with BM and verified the above prognostic scoring classification system.

\section{Materials and Methods}

The data of 7098 consecutive patients with cervical cancer treated in Peking Union Medical College Hospital from January 2000 to December 2019 were analyzed retrospectively. Twenty-seven patients were diagnosed with BM from cervical cancer, and three patients were lost to followup. The 24 cases of BM from cervical cancer included in the study were diagnosed by clinical images or pathology.

The date and cause of death for all patients were recorded. The survival time of BM was calculated from the date of diagnosis of BM to the date of death from any cause. The clinical data included histopathology at the time of initial diagnosis; FIGO stage; control of primary cervical lesions; time interval from diagnosis of cervical cancer to a diagnosis of BM; age and KPS at BM diagnosis; volume, number and location of the $\mathrm{BM}$; presence of meningeal metastasis; presence of extracranial metastasis; and therapeutic schedule after the diagnosis of BM including surgery, radiotherapy, and chemotherapy.

The median survival time after diagnosis of BM was calculated using Kaplan-Meier curve analysis. The Log rank test was used to compare differences in survival. The variables with p-value $<0.1$ in univariate analysis were included in Cox multivariate regression analysis. Differences in multivariate analysis were assumed to be statistically significant when p-value was $<0.05$. All statistical analyses were performed using IBM SPSS Statistics version 19.0.

\section{Results}

\section{Patient Characteristics}

The incidence of BM was $0.38 \%$. The mean age at BM diagnosis was 48.9 years (median 47.5 years, 31.4-71.5 years), and KPS was 70 (20-100). The main symptoms were headache, dizziness, malignant vomiting, hypomnesis, ataxia, diplopia, etc. The mean time interval between the diagnosis of cervical cancer to the identification of BM was 25.4 months (median 26.3 months, 0-57.4 months). All patients received surgery, radiotherapy or radiochemotherapy at the time of initial diagnosis of cervical cancer. After initial treatment, the primary tumor was controlled in 20 cases $(83.3 \%)$.

At the time of initial diagnosis of cervical cancer and $\mathrm{BM}$ diagnosis, the clinicopathological features of the
Table I The Clinicopathological Features of 24 Patients

\begin{tabular}{|c|c|c|}
\hline \multicolumn{2}{|l|}{ Variables } & $\begin{array}{l}\text { All } \\
\text { Patients } \\
\text { (\%) }\end{array}$ \\
\hline $\begin{array}{l}\text { Age at BM diagnosis } \\
\text { (years) }\end{array}$ & $\begin{array}{l}\leq 65 \\
>65\end{array}$ & $\begin{array}{l}22(91.7) \\
2(8.3)\end{array}$ \\
\hline KPS at BM diagnosis & $\begin{array}{l}\geq 70 \\
<70\end{array}$ & $\begin{array}{l}16(66.7) \\
8(33.3)\end{array}$ \\
\hline 2018 FIGO stage & $\begin{array}{l}\text { IBI } \\
\text { IIB } \\
\mathrm{IIICI} \\
\mathrm{IIIC2} \\
\text { IVB }\end{array}$ & $\begin{array}{l}4(16.7) \\
3(12.5) \\
7(29.2) \\
5(20.8) \\
5(20.8)\end{array}$ \\
\hline Pathology & $\begin{array}{l}\text { Squamous carcinoma } \\
\text { Adenocarcinoma } \\
\text { Adenosquamous } \\
\text { carcinoma } \\
\text { Neuroendocrine } \\
\text { carcinoma }\end{array}$ & $\begin{array}{l}\text { I } 4(58.3) \\
\text { I (4.2) } \\
\text { I ( }(4.2) \\
8(33.3)\end{array}$ \\
\hline Number of BMs & $\begin{array}{l}1 \\
2 \\
3 \\
4 \\
5 \\
>10 \\
\text { Unknown }\end{array}$ & $\begin{array}{l}8(33.3) \\
2(8.3) \\
3(12.5) \\
2(8.3) \\
2(8.3) \\
2(8.3) \\
5(20.8)\end{array}$ \\
\hline Meningeal metastasis & $\begin{array}{l}\text { Yes } \\
\text { No }\end{array}$ & $\begin{array}{l}2(8.3) \\
22(91.7)\end{array}$ \\
\hline Location of BM & $\begin{array}{l}\text { Above the tentorium } \\
\text { Below the tentorium } \\
\text { Both above and below the } \\
\text { tentorium } \\
\text { Unknown locations }\end{array}$ & $\begin{array}{l}\text { II (45.8) } \\
2(8.3) \\
6(25) \\
5(20.8)\end{array}$ \\
\hline Extracranial metastasis & $\begin{array}{l}\text { Yes } \\
\text { No }\end{array}$ & $\begin{array}{l}20(83.3) \\
4(16.7)\end{array}$ \\
\hline $\begin{array}{l}\text { Control of primary } \\
\text { cervical lesions }\end{array}$ & $\begin{array}{l}\text { Yes } \\
\text { No }\end{array}$ & $\begin{array}{l}20(83.3) \\
4(16.7)\end{array}$ \\
\hline
\end{tabular}

Abbreviations: BM, brain metastasis; KPS, Karnofsky performance status.

patients are shown in Table 1. The average volume of BMs was $27.6 \mathrm{~cm}^{3}$ (median $18.7 \mathrm{~cm}^{3}, 0.2-81.5 \mathrm{~cm}^{3}$ ). Twenty patients (83.3\%) had extracranial metastasis, most of occurred in the lung, liver, bone, lymph node, or soft tissue. All treatment characteristics of the patients are shown in Table 2.

In addition, 24 patients were evaluated by the prognosis scoring classification systems for BM. The results are shown in Table 3. 
Table 2 Treatment Characteristics of 24 Patients

\begin{tabular}{|c|c|c|c|}
\hline \multicolumn{2}{|l|}{ Variables } & \multicolumn{2}{|c|}{ All Patients (\%) } \\
\hline \multirow{6}{*}{$\begin{array}{l}\text { Therapeutic } \\
\text { schedule }\end{array}$} & RT alone & $\mathrm{I}(4.2)$ & \multirow[t]{5}{*}{$18(75)$} \\
\hline & S followed by RT & $\mathrm{I}(4.2)$ & \\
\hline & CT alone & $3(12.5)$ & \\
\hline & $\mathrm{RT}$ and $\mathrm{CT}$ & $10(41.7)$ & \\
\hline & $\mathrm{S}$ followed by RT and CT & $3(12.5)$ & \\
\hline & Palliative care & \multicolumn{2}{|l|}{$6(25)$} \\
\hline \multirow[t]{2}{*}{ RT status } & WBRT $\pm S I B$ & \multicolumn{2}{|l|}{$9(37.5)$} \\
\hline & SRT & \multicolumn{2}{|l|}{$6(25)$} \\
\hline
\end{tabular}

Abbreviations: $\mathrm{BM}$, brain metastasis; $\mathrm{S}$, surgery; $\mathrm{RT}$, radiotherapy; $\mathrm{CT}$, chemotherapy; SIB, simultaneous integrated boost; SRT, stereotactic radiotherapy; WBRT, whole-brain radiotherapy.

\section{Survival Analysis}

The mean survival time of all 24 cervical cancer patients with $\mathrm{BM}$ after diagnosis was 7.2 months (median 6.2 months, 0.1-21.2 months). The survival curve is shown in Figure 1. Among them, 18 patients (75\%) died of cervical cancer due to systemic progression, and 6 patients (25\%) died of BM. Among the 15 patients who delivered radiotherapy, 11 patients $(73.3 \%)$ had controlled intracranial lesions, and 4 patients (26.7\%) experienced progression.

In the univariate analysis, the histopathology of neuroendocrine cancer, FIGO stage, KPS at BM diagnosis, and treatment strategy (surgery, radiotherapy or

Table 3 The Evaluated Results of 24 Patients by Prognostic Scoring Classification Systems for BM

\begin{tabular}{|l|l|l|}
\hline \multicolumn{2}{|l|}{$\begin{array}{l}\text { Prognosis } \\
\text { Classification } \\
\text { Systems for BM }\end{array}$} & All Patients (\%) or Median Score (Range) \\
\hline \multirow{2}{*}{ RPA } & Grade I & $2(8.3)$ \\
\cline { 2 - 3 } & Grade II & $14(58.3)$ \\
\cline { 2 - 3 } & Grade III & $8(33.3)$ \\
\hline GPA & $2.0(0.5-3)$ \\
\hline Uterine-GPA & $2.0(0-4)$ \\
\hline BS-BM & $1.5(0-3)$ \\
\hline GGS & $1.0(0-3)$ \\
\hline
\end{tabular}

Abbreviations: BM, brain metastasis; RPA, recursive partition analysis; GPA, Graded Prognostic Assessment; uterine-GPA, the GPA for uterine cancer; BS-BM, basic score for brain metastasis; GGS, Golden Grading System.

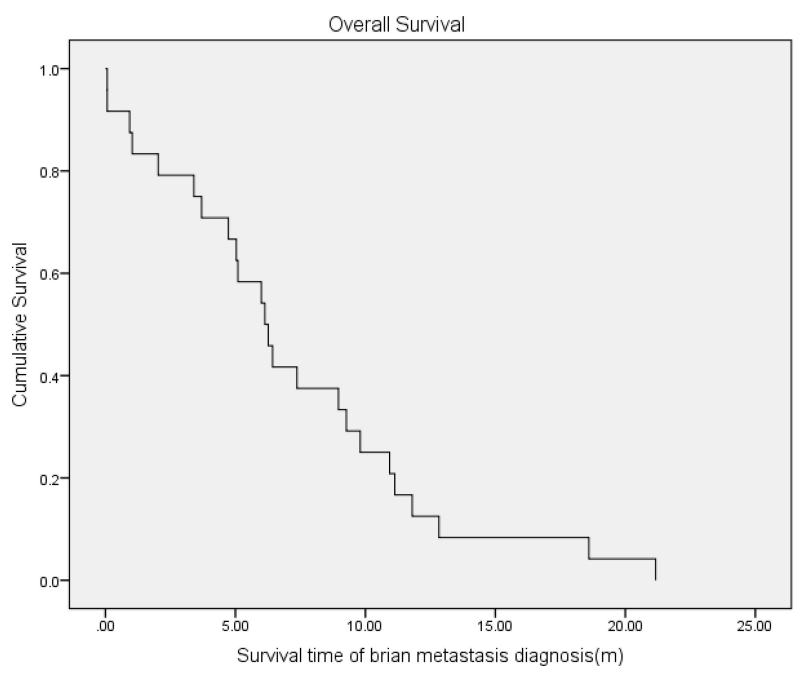

Figure I Survival curve of cervical cancer patients with BM (months).

chemotherapy) were identified to have prognostic significance regarding the survival of patients with $\mathrm{BM}$ from cervical cancer $(\mathrm{P}<0.05)$. The age at $\mathrm{BM}$ diagnosis and extracranial metastasis were close to statistical significance, as shown in Table 4.

Table 4 Univariate Analysis of Cervical Cancer Patients with BM

\begin{tabular}{|c|c|c|c|c|}
\hline \multicolumn{2}{|l|}{ Variables } & $\begin{array}{l}\text { Mean Survival } \\
\text { Time } \\
\text { (Months) }\end{array}$ & P-value & $\chi^{2}$ \\
\hline $\begin{array}{l}\text { Age at BM diagnosis } \\
\text { (years) }\end{array}$ & $\begin{array}{l}\leq 65 \\
>65\end{array}$ & $\begin{array}{l}7.6 \\
3.0\end{array}$ & 0.056 & 3.639 \\
\hline KPS at BM diagnosis & $\begin{array}{l}\geq 70 \\
<70\end{array}$ & $\begin{array}{l}8.8 \\
4.0\end{array}$ & 0.024 & 5.098 \\
\hline $\begin{array}{l}\text { Histopathology } \\
\text { (neuroendocrine } \\
\text { cancer) }\end{array}$ & $\begin{array}{l}\text { Yes } \\
\text { No }\end{array}$ & $\begin{array}{l}10.5 \\
5.5\end{array}$ & 0.018 & 5.584 \\
\hline $2018 \mathrm{FIGO}$ stage & $\begin{array}{l}\text { IBI } \\
\text { IIB- } \\
\text { IVB }\end{array}$ & $\begin{array}{l}14.2 \\
5.8\end{array}$ & 0.014 & 6.011 \\
\hline $\begin{array}{l}\text { Extracranial } \\
\text { metastasis }\end{array}$ & $\begin{array}{l}\text { Yes } \\
\text { No }\end{array}$ & $\begin{array}{l}8.0 \\
3.4\end{array}$ & 0.054 & 3.706 \\
\hline Treatment status & $\begin{array}{l}\text { Yes } \\
\text { No }\end{array}$ & $\begin{array}{l}9.0 \\
1.8\end{array}$ & 0 & 23.8 \\
\hline $\begin{array}{l}\text { Local treatment } \\
\text { status (surgery and } \\
\text { RT) }\end{array}$ & $\begin{array}{l}\text { Yes } \\
\text { No }\end{array}$ & $\begin{array}{l}9.6 \\
3.2\end{array}$ & 0 & 12.389 \\
\hline Chemotherapy & $\begin{array}{l}\text { Yes } \\
\text { No }\end{array}$ & $\begin{array}{l}9.2 \\
3.2\end{array}$ & 0.001 & 10.665 \\
\hline
\end{tabular}

Abbreviations: BM, brain metastasis; RT, radiotherapy. 
Table 5 Multivariate Analysis of Cervical Cancer Patients with BM

\begin{tabular}{|l|l|l|l|l|l|l|l|l|}
\hline Variables & B & SE & Wald & df & P-value & \multicolumn{2}{l|}{ Exp(B) } & \multicolumn{2}{|l|}{ 95\% CI for Exp(B) } \\
\cline { 3 - 8 } & & & & & & & Lower & Upper \\
\hline KPS at BM diagnosis & -.037 & 0.018 & 4.072 & $I$ & 0.044 & 0.964 & 0.930 & 0.999 \\
RT & 1.302 & 0.529 & 6.052 & $I$ & 0.014 & 3.676 & 1.303 & 10.372 \\
CT & 1.184 & 0.582 & 4.131 & I & 0.042 & 3.266 & 1.043 & 10.226 \\
\hline
\end{tabular}

Abbreviations: BM, brain metastasis; KPS, Karnofsky performance status; RT, radiotherapy; CT, chemotherapy.

Table 6 Mean Survival Time by Different Therapeutic Schedules in 24 Patients

\begin{tabular}{|c|c|c|c|c|}
\hline Therapeutic Schedule & $\begin{array}{l}\text { All Patients } \\
\text { (\%) }\end{array}$ & $\begin{array}{l}\text { Mean Survival Time } \\
\text { (Months) }\end{array}$ & $\begin{array}{l}\text { P-value for Treatment } \\
\text { Group }\end{array}$ & $\begin{array}{l}\text { P-value for All } \\
\text { Patients }\end{array}$ \\
\hline S followed by SRT and CT & $\mathrm{I}(4.2)$ & 9.3 & \multirow[t]{8}{*}{0.577} & \multirow[t]{9}{*}{0} \\
\hline$S$ followed by WBRT and CT & $2(8.3)$ & 16.1 & & \\
\hline$S$ followed by WBRT & I (4.2) & 6.3 & & \\
\hline SRT alone & $\mathrm{I}(4.2)$ & 9.0 & & \\
\hline SRT and CT & $4(16.7)$ & 6.5 & & \\
\hline WBRT and CT & $2(8.3)$ & 9.6 & & \\
\hline WBRT with SIB and CT & $4(16.7)$ & 10.5 & & \\
\hline CT alone & $3(12.5)$ & 6.2 & & \\
\hline Palliative care & $6(25)$ & 1.8 & & \\
\hline
\end{tabular}

Abbreviations: S, surgery; RT, radiotherapy; CT, chemotherapy; SIB, simultaneous integrated boost; SRT, stereotactic radiotherapy; WBRT, whole-brain radiotherapy.

The above variables with $\mathrm{P}<0.1$ in univariate analysis were included in Cox multivariate regression analysis. In the multivariate analysis, KPS, chemotherapy, and radiotherapy were identified as independent prognostic factors for survival, as shown in Table 5. The mean survival times by the different therapeutic schedules are shown in Table 6.

Because the treatment options need to consider the patient's systemic lesions, the number of BM and pathological types, we conducted stratified analysis on the number of BM, whether extracranial metastases and neuroendocrine carcinoma in the following analysis.

In the stratified analysis on the number of BMs, all patients with $\mathrm{BMs}>3$ underwent WBRT. In $\mathrm{BMs} \leq 3$ group, the proportion of patients undergoing local treatment (SRT \pm surgery) was significantly higher than that of patients undergoing WBRT $\left(50 \%\right.$ vs $\left.25 \%, \mathrm{P}=0.011, \chi^{2}=9\right)$. The mean survival times of the different therapeutic schedules for patients with BMs $>3$ and $\leq 3$ are shown in Table 7 .

Among the eight patients with neuroendocrine carcinoma, five patients had $\mathrm{BMs} \leq 3$, two patients had $\mathrm{BMs}>3$, and the BMs of one patient was unknown. All patients received chemotherapy. Of the six patients who underwent radiotherapy, four underwent WBRT and two underwent SRT.

Among the 20 patients with extracranial metastasis, 17 received aggressive treatment including surgery, radiotherapy or chemotherapy, and 3 only received palliative care; of the 4 patients without extracranial metastasis, only 1 received treatment, and the remaining 3 received palliative care. Tables 7 and 8 respectively show the mean survival times by different therapeutic schedules and by the treatment group and palliative care group for the patients with neuroendocrine carcinoma and extracranial metastasis.

During the verification for the prognostic scoring classification systems of BM, only in the RPA, the comparison of grade II and grade III showed significant differences $(\mathrm{P}=0.014$, $\left.\chi^{2}=6.077\right)$. In the other prognostic scoring classification systems, such as GPA, uterine-GPA, BS-BM, and GGS, the $\mathrm{P}$-values were $0.584,0.518,0.893$, and 0.234 , respectively.

\section{Discussion}

Cervical cancer is the most common cancer in women. The common metastatic sites are the lymph nodes, liver, 


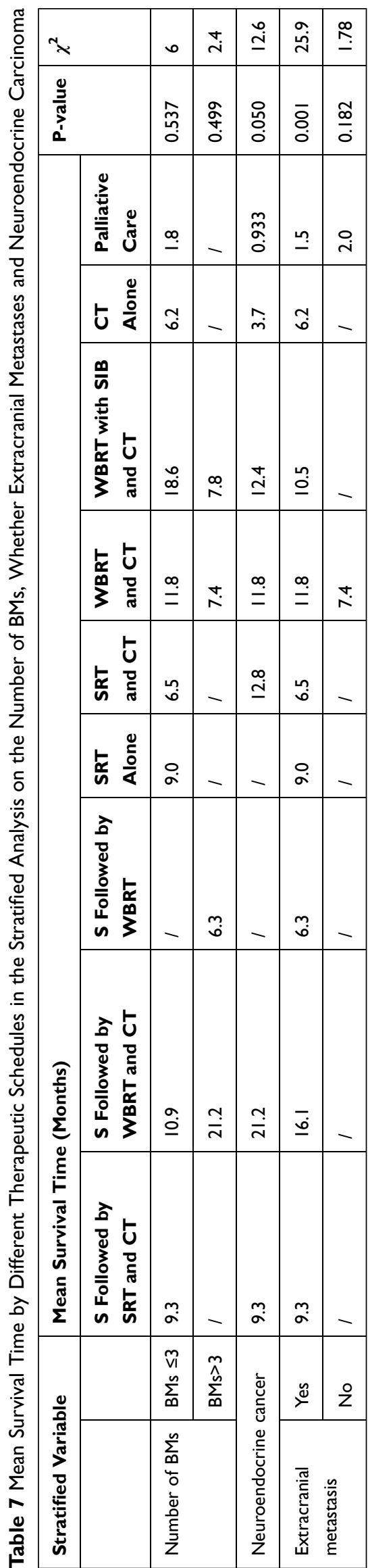

Table 8 Mean Survival Time (Months) by Treatment Group and Palliative Care Group for the Patients with Neuroendocrine Carcinoma and Extracranial Metastasis

\begin{tabular}{|l|l|l|l|l|l|l|}
\hline & \multicolumn{3}{|l|}{$\begin{array}{l}\text { Extracranial } \\
\text { Metastasis }\end{array}$} & \multicolumn{3}{l|}{$\begin{array}{l}\text { Neuroendocrine } \\
\text { Cancer }\end{array}$} \\
\cline { 2 - 7 } & Yes & No & P-value & Yes & No & P-value \\
\hline $\begin{array}{l}\text { Treatment group } \\
\text { Palliative care } \\
\text { group }\end{array}$ & 9.1 & 7.4 & 0.670 & 11.9 & 7.2 & 0.026 \\
\hline
\end{tabular}

lung, bone, etc. BM is very rare. The incidence of BM from cervical cancer is $0.4 \%-2.3 \% \cdot{ }^{1-8} \mathrm{An}$ autopsy study reported that $3-10 \%$ of cervical cancer patients had BM. ${ }^{16}$ Because of the very low incidence of $\mathrm{BM}$ in cervical cancer patients, routine brain imaging is not a part of the guidelines for surveillance of posttreatment cervical cancer patients as issued by the National Comprehensive Cancer Network. Most cases of BM were diagnosed with brain imaging after neurological symptoms. At present, there is no clear prognosis scoring classification system or therapeutic guidelines. BM is usually treated with multimodal therapy using surgery, radiotherapy, and chemotherapy. The clinical characteristics, prognostic factors, and treatment of BM from cervical cancer are discussed as follows.

\section{Clinical Characteristics}

It has been reported that the mean age of BM from cervical cancer is 45-50 years old. ${ }^{4,5,16,17}$ Most of the cases occur approximately 1.5-2 years after the diagnosis of cervical cancer. ${ }^{4,5,10}$ The prognosis is poor, and the mean survival time ranges from 2 to 8 months. ${ }^{5,8,11-15}$ The clinical manifestations are nervous system symptoms such as headache, dizziness, malignant vomiting, muscle weakness, ataxia, diplopia, etc. The most common histopathology of BM is squamous cell carcinoma. ${ }^{5}$ Although cervical neuroendocrine carcinoma is rare, the risk of BM is as high as $20 \% .{ }^{18}$ Therefore, the histopathology of neuroendocrine carcinoma is related to survival in many pieces of literature. ${ }^{5,8}$ The above characteristics are consistent with the results of this study.

\section{Prognostic Factors}

It has been reported that the prognosis of cervical cancer patients with BM is affected by many factors. Age, KPS, histopathology, stage, control of primary cervical lesions, time interval from diagnosis of cervical cancer to the diagnosis of $\mathrm{BM}$, number of $\mathrm{BM}$ and tumor size, 
extracranial metastasis, treatment factors (radiotherapy, chemotherapy, surgery, etc. $)^{2,4-9,12-14,16,17,19-21}$ are prognostic factors related to the BM of cervical cancer. Additionally, molecular biology studies have shown that some of the molecular characteristics in tissue samples ${ }^{22,23}$ are also related to survival. In our univariate analysis, histopathology of neuroendocrine cancer, the early stage of the 2018 FIGO stage, age $<65$ years and KPS $\geq 70$ at $\mathrm{BM}$ diagnosis, extracranial metastasis, and aggressive treatment had statistical significance. In the multivariate analysis, only higher KPS, radiotherapy, and chemotherapy provided significant benefits. These results are consistent with the above literature.

In further stratified analysis on whether neuroendocrine carcinoma and extracranial metastasis group, the survival time of palliative care was 0.9 months vs. 1.9 months $(\mathrm{P}=0.583)$ and 1.5 months vs. 2.0 months $(\mathrm{P}=0.486)$, respectively. After aggressive treatment, the survival time of the two groups was similar and was even higher than that of the control group (11.9 vs. 7.2months, $\mathrm{P}=0.026$; 9.1 vs. 7.4 months, $\mathrm{P}=0.670$ ). Therefore, for patients with a high KPS score, aggressive treatment can significantly improve survival, and similar conclusions have been obtained in other studies. ${ }^{8}$

\section{Therapeutic Schedule}

At present, the treatment options of BM from cervical cancer mainly include surgery, WBRT, SRS (stereotactic surgery), SRT, or chemotherapy. For patients with high KPS scores, surgery or SRS combined with WBRT and sequential chemotherapy has been proven to increase survival time in many pieces of literature. ${ }^{4,5,8,11,13,17}$ Some authors strongly suggest that surgery followed by radiotherapy is an effective treatment for patients with solitary BM that prolongs survival. $4,5,9,11,15,19,20,24$ The result of our study shows that surgery followed by SRT and chemotherapy may be better than the combination of SRT and chemotherapy; surgery followed by WBRT and chemotherapy may be better than surgery followed by SRT and chemotherapy; surgery followed by WBRT and chemotherapy may be better than surgery followed by WBRT; WBRT with SIB and chemotherapy may be better than WBRT and chemotherapy. Although there was no significant difference in the above data $(\mathrm{P}=0.577)$, there was a numerical advantage in terms of survival time. It is suggested that only the combination of local treatment such as radiotherapy or surgery and chemotherapy may improve the survival time, which is better than that with any single treatment. ${ }^{4,6,12}$
In our study, the proportion of patients undergoing local treatment (SRT \pm surgery) was significantly higher than that of patients undergoing WBRT (50\% vs. $25 \%$, $\mathrm{P}=0.011$ ) for the patients with $\mathrm{BMs} \leq 3$. On the other hand, all patients with $\mathrm{BMs}>3$ underwent WBRT. In the previous literature, for patients with surgical indications, surgery followed by radiotherapy and chemotherapy can improve survival time. ${ }^{9,16,17,21}$ At present, of the radiation interventions, it was believed that WBRT will benefit survival. ${ }^{7}$ This also supports our treatment options. Moreover, of our data, the higher the total dose of radiation was, the greater the potential survival benefit maybe. Additionally, it has been reported that SRS combined with WBRT can alleviate the neurological symptoms caused by BM. ${ }^{11}$

\section{Prognosis Scoring Classification System of Cervical Cancer with BM}

At present, there are many prognostic scoring classification systems in the clinic, and RPA and GPA are the most commonly used. Because of the differences in the biological characteristics of BM of a different histology, a disease-specific GPA (disease-specific GPA) has been proposed. The abovementioned prognosis scoring classification systems of BM are mainly based on cases with WBRT. Additionally, the BS-BM and GGS are based on SRT or combined with WBRT. In 2012, the diseasespecific GPA can also be used as a prognostic scoring classification system for BM based on SRT. Japanese scholars put forward the uterine-GPA for uterine cancer (endometrial cancer and cervical cancer) in 2017. ${ }^{14}$

In this study, RPA, GPA, uterine-GPA, BS-BM, and GGS were used to predict prognosis. They did not show significant statistical significance except for RPA because our results were more consistent with those predictive factors in RPA. These results were consistent with the previous literature. ${ }^{6,17}$ Most of the data in these prognosis scoring classification systems were from lung cancer and other common cancers, so it may not be suitable for patients with BM from cervical cancer. Hayashi et al proposed that the final prognostic factors in uterine-GPA are completely different from those in this study. Therefore, the prognosis scoring classification system of BM from cervical cancer needs further study with a larger sample for improvement.

Because of the low incidence of BM from cervical cancer, the data in this study were from the same center, which could introduce center bias. However, compared 
with the data in similar literature from a single cancer treatment center, the number of cases in this study is the largest. The results of this study may provide important evidence for the treatment of cervical cancer patients with BM.

In conclusion, when patients with BM from cervical cancer have good performance status and undergo comprehensive treatment, such as radiotherapy and chemotherapy, their survival time could be significantly prolonged. Patients with surgical indications may get better survival by postoperative radiotherapy and chemotherapy. Patients with BMs $\geq 3$ may get better survival by WBRT. But further studies are needed regarding the selection of surgical indications and radiotherapy modes. The prognosis scoring classification system for BM from cervical cancer needs to be improved.

\section{Ethics and Consent Statement}

This study was conducted in accordance with the Declaration of Helsinki. This study was approved by the Ethics Review Committee of Peking Union Medical College Hospital, Chinese Academy of Medical Sciences [Protocol number S-K1298]. Informed consent was obtained from each patient or his/her guardian prior to initiating the treatment.

\section{Funding}

The study is supported by the National Natural Science Foundation of China (No. U19A2064), Non-profit Central Research Institute Fund of Chinese Academy of Medical Sciences (No. 2019XK320046) and Grants from funds for Peking Union Medical College Postgraduate Education Reform Program (No. 10023201900104).

\section{Disclosure}

All the authors declare that they have no conflicts of interest.

\section{References}

1. Divine LM, Kizer NT, Hagemann AR, et al. Clinicopathologic characteristics and survival of patients with gynecologic malignancies metastatic to the brain. Gynecol Oncol. 2016;142(1):76-82. doi:10.1016/j.ygyno.2016.04.030

2. Teke F, Tunc SY, Teke M, et al. The impact of the stage and tumor size on rare brain metastasis of cervical cancer. Turk Neurosurg. 2016;26:818-823.

3. Peters P, Bandi H, Efendy J, Perez-Smith A, Olson S. Rapid growth of cervical cancer metastasis in the brain. J Clin Neurosci. 2010;17 (9):1211-1212. doi:10.1016/j.jocn.2010.01.021
4. Chura JC, Shukla K, Argenta PA. Brain metastasis from cervical carcinoma. Int J Gynecol Cancer. 2007;17:141-146.

5. Hwang JH, Yoo HJ, Lim MC, et al. Brain metastasis in patients with uterine cervical cancer. J Obstet Gynaecol Res. 2013;39(1):287-291. doi:10.1111/j.1447-0756.2012.01927.x

6. Zhang JX, Wang SZ, Li B, Zhang ZY. Clinical analysis of 23 gynecologic carcinoma patients with brain metastasis. Zhonghua $Y i$ Xиe Za Zhi. 2016;96(23):1843-1846.

7. Kim SB, Hwang K, Joo JD, Han JH, Kim YB, Kim CY. Outcomes in 20 gynecologic cancer patient with brain metastasis: a single institution retrospective study. Brain Tumor Res Treat. 2017;5:87-93. doi:10.14791/btrt.2017.5.2.87

8. Kim H, Lee KK, Heo MH, Kim JY. The prognostic factors influencing overall survival in uterine cervical cancer with brain metastasis. Korean J Intern Med. 2019;34:1324-1332. doi:10.3904/ kjim.2018.051

9. Piura E, Piura B. Brain metastases from cervical carcinoma: overview of pertinent literature. Eur J Gynaecol Oncol. 2012;33:567-573.

10. Ikeda S, Yamada T, Katsumata N, et al. Cerebral metastasis in patients with uterine cervical cancer. Jpn J Clin Oncol. 1998;28 (1):27-29. doi:10.1093/jjco/28.1.27

11. Chung S-B, Jo K-I, Seol H-J, Nam D-H, Lee J-I. Radiosurgery to palliate symptoms in brain metastases from uterine cervix cancer. Acta Neurochir (Wien). 2013;155(3):399-405. doi:10.1007/s00701012-1576-X

12. Guangwen Y. Clinical analysis of 25 cases of gynecological malignant tumor with brain metastasis. Chin J Obstet Gynecol. 2012;3.

13. Kim YZ, Kwon JH, Lim S. A clinical analysis of brain metastasis in gynecologic cancer: a retrospective multi-institute analysis. J Korean Med Sci. 2015;30(1):66-73. doi:10.3346/jkms.2015.30.1.66

14. Hayashi N, Takahashi H, Hasegawa $\mathrm{Y}$, et al. A nationwide multi-institutional retrospective study to identify prognostic factors and develop a graded prognostic assessment system for patients with brain metastases from uterine corpus and cervical cancer. $B M C$ Cancer. 2017;17(1):397. doi:10.1186/s12885-017-3358-6

15. Agrawal A, Kumar A, Sinha AK, Kumar M, Pandey SR, Khaniya S. Intracranial metastases from carcinoma of the cervix. Singapore Med J. 2007;48:e154-e156.

16. Branch BC, Henry J, Vecil GG. Brain metastases from cervical cancer - a short review. Tumori J. 2014;100(5):e171-e179. doi: $10.1177 / 1660.18186$

17. Gressel GM, Lundsberg LS, Altwerger G, et al. Factors predictive of improved survival in patients with brain metastases from gynecologic cancer: a single institution retrospective study of 47 cases and review of the literature. Int $J$ Gynecol Cancer. 2015;25(9):1711-1716. doi:10.1097/IGC.0000000000000554

18. Weed JC Jr, Graff AT, Shoup B, Tawfik O. Small cell undifferentiated (neuroendocrine) carcinoma of the uterine cervix. J Am Coll Surg. 2003;197(1):44-51. doi:10.1016/S1072-7515(03)00120-0

19. Chura JC, Marushin R, Boyd A, Ghebre R, Geller MA, Argenta PA. Multimodal therapy improves survival in patients with CNS metastasis from uterine cancer: a retrospective analysis and literature review. Gynecol Oncol. 2007;107(1):79-85. doi:10.1016/j.ygyno.2007.05.027

20. Cordeiro JG, Prevedello DM, da Silva Ditzel LF, Pereira CU, Araújo JC. Cerebral metastasis of cervical uterine cancer: report of three cases. Arq Neuropsiquiatr. 2006;64:300-302. doi:10.1590/ S0004-282X2006000200023

21. Tangjitgamol S, Levenback CF, Beller U, Kavanagh JJ. Role of surgical resection for lung, liver, and central nervous system metastases in patients with gynecological cancer: a literature review. Int $J$ Gynecol Cancer. 2004;14:399-422. doi:10.1111/j.1048891x.2004.14326.x

22. Zhang W, He W, Shi Y, et al. High expression of KIF20A is associated with poor overall survival and tumor progression in early-stage cervical squamous cell carcinoma. PLoS One. 2016;11(12):e0167449. doi:10.1371/journal.pone.0167449 
23. Zhao M, Li Y, Wei X, et al. Negative immune factors might predominate local tumor immune status and promote carcinogenesis in cervical carcinoma. Virol J. 2017;14(1):5. doi:10.1186/s12985-0160670-8
24. Brown Iii JV, Epstein HD, Kim R, et al. Rapid manifestation of CNS metastatic disease in a cervical carcinoma patient: a case report. Oncology. 2007;73(3-4):273-276. doi:10.1159/000127426

\section{Publish your work in this journal}

Cancer Management and Research is an international, peer-reviewed open access journal focusing on cancer research and the optimal use of preventative and integrated treatment interventions to achieve improved outcomes, enhanced survival and quality of life for the cancer patient.
The manuscript management system is completely online and includes a very quick and fair peer-review system, which is all easy to use. Visit http://www.dovepress.com/testimonials.php to read real quotes from published authors. 